\title{
Effectiveness of targeting fathers for breastfeeding promotion: systematic review and meta-analysis
}

Pasyodun Koralage Buddhika Mahesh ${ }^{1 *}$ (D, Moraendage Wasantha Gunathunga ${ }^{2}$, Suriyakumara Mahendra Arnold ${ }^{1}$, Chintha Jayasinghe ${ }^{3}$, Sisira Pathirana ${ }^{4}$, Mohamed Fahmy Makarim ${ }^{5}$, Pradeep Malaka Manawadu ${ }^{5}$ and Sameera Jayan Senanayake ${ }^{6}$

\begin{abstract}
Background: Further research gaps exist in relation to the promotion of breastfeeding. Robust scientific evidence obtained by a meta-analysis would provide objectively summarized data while enabling the assessment of consistency of findings. This review includes the first documented meta-analysis done on the effectiveness of targeting fathers for promoting breastfeeding (BF). Assessments have been done for a primary outcome and for six more secondary outcomes.

Methods: PubMed, EMBASE, Google Scholar, CENTRAL databases and unpublished researches were searched. Selections of randomized-controlled trials and quasi-experimental studies were done in three rounds. Heterogeneity and potential publication bias were assessed. Eight studies were included in meta-analysis and others in narrative synthesis of the outcomes. Pooling was done with the Mental- Haenszel method using risk ratio (RR). Summary-ofFindings table was composed by Review-Manager (version 5.3) and GRADEproGDT applications. Subsequent sensitivity analysis was done.

Results: Selected eight interventional studies included 1852 families. Exclusive BF at six months was significantly higher $(\mathrm{RR}=2.04, \mathrm{Cl}=1.58-2.65)$ in the intervention groups. The $\mathrm{RR}$ at 4 months was $1.52(\mathrm{Cl}=1.14$ to 2.03$)$. Risk of full-formula-feeding ( $R R=0.69, \mathrm{Cl}=0.52-0.93)$ and the occurrence of lactation-related problems were lower in the intervention groups ( $R R=0.24, \mathrm{Cl}=0.10-0.57)$. More likelihood of rendering support in BF-related issues was seen in intervention groups $(\mathrm{RR}=1.43, \mathrm{Cl}=1.22-1.68)$. Increase of maternal knowledge and favorable attitudes on $\mathrm{BF}$ were higher in the intervention groups ( $P \leq ; 0.001$ ). The quality of evidence according to GRADE was "low" (for one outcome), "moderate" (for four outcomes), and "high" (for two outcomes).
\end{abstract}

Conclusions: Targeting fathers in promotion of BF has provided favorable results for all seven outcomes with satisfactory quality of evidence.

This review was registered in the PROSPERO-registry (ID: 2017-CRD42017076163) prior to its commencement.

Keywords: Breastfeeding, Fathers' influence on breastfeeding, Exclusive breastfeeding, Breastfeeding promotion, Infant nutrition, Partner support in breastfeeding

\footnotetext{
* Correspondence: buddhikamaheshpk@gmail.com

${ }^{1}$ Office of Regional Director of Health Services, Colombo, Sri Lanka

Full list of author information is available at the end of the article
}

(c) The Author(s). 2018 Open Access This article is distributed under the terms of the Creative Commons Attribution 4.0 International License (http://creativecommons.org/licenses/by/4.0/), which permits unrestricted use, distribution, and reproduction in any medium, provided you give appropriate credit to the original author(s) and the source, provide a link to the Creative Commons license, and indicate if changes were made. The Creative Commons Public Domain Dedication waiver (http://creativecommons.org/publicdomain/zero/1.0/) applies to the data made available in this article, unless otherwise stated. 


\section{Background}

Breast milk is regarded as the best source of nutrition a newborn can get [1]. It provides favorable outcomes to the baby as well as to the mother [2-6]. These outcomes are not only limited to growth-related, immunological, and economic benefits, but also extend to a larger scope with the assumption of influencing genetic-dynamics as well [7]. Furthermore, breastfeeding has been found to be associated with favorable adult outcomes like prevention of chronic non-communicable diseases which are becoming global epidemics [8-11]. The World Health Organization (WHO) and the United Nations Children's Fund (UNICEF) recommend an exclusive breastfeeding (EBF) period of 6 months for all settings [1, 12-14]. Since 2001, this recommended duration has not been changed until now $[15,16]$. Yet in many communities, the breastfeeding norms are being challenged $[17,18]$. It has been mentioned that in certain settings of low and middle-income countries, the cumulative prevalence of EBF in babies younger than 6 months is less than $40 \%$ [6]. In many of high-income countries, the duration of EBF period is shorter compared to resource-poor settings [6].

There are certain factors that increase as well as decrease the duration of EBF. Lack of family and social support have been determined as detrimental factors associated with the exclusivity and duration of breastfeeding $[1,19]$. In addition, the occurrence of lactationrelated problems like breast engorgement, sore nipples, incorrect attachment, and promotion of formula feeding have been recognized as negatively influencing factors of breastfeeding [20, 21]. In contrast, higher knowledge of mothers on breastfeeding helps to promote it [20].

Promotion of breastfeeding needs multilevel supportive measures with interventions being implemented through several channels [17]. Fathers have been named as one recommended target in promoting breastfeeding $[22,23]$. Qualitative research findings have revealed some domains of the father's role in breastfeeding [24]. Yet, literature suggests that "fathers or male partners" have not been given adequate emphasis in the promotion of breastfeeding $[18,25]$.

The available research findings of observational studies point towards a positive correlation between the support of the male partner and the likelihood of continuation of breastfeeding $[18,25,26]$. Even the perceived support of the partner is linked with favorable levels of self-efficacy [27]. In addition to their support, the attitudes of the husband have been documented as determinants of breast feeding self-efficacy [28, 29]. In contrast, some literature does not recommend the "broad application of male involvement" in promoting EBF [30]. A cohort study has documented that though their emotional support does, the practical support of fathers as not being associated with better breastfeeding [31]. Similarly, a study done in India has revealed that though the fathers' attitudes support breast feeding, they do not influence the duration of EBF [32].

Child nutrition programs require much more investments and commitments globally [13]. At the same time, more scientific literature is needed in determining the effectiveness of interventions on breastfeeding as there are issues on the generalizability of currently available evidence [33]. The WHO has highlighted that more scientific evidences are needed "across different regions, countries, population groups and contexts, in order to adequately and sensitively protect, promote and support breastfeeding." [34]. Meta-analysis of systematically reviewed data would provide objectively-summarized precise data and enable assessing the consistency of findings [35]. It is recommended that the use of randomized control studies as an ideal strategy in determining the effectiveness of interventions which target breastfeeding [36, 37]. When randomization is not possible, quasi-experimental studies may produce better evidence than observational studies in evaluating the effectiveness of interventions [38, 39].

The present review included assessing a primary outcome as well as six secondary outcomes. First, a specific objective was to conduct a meta-analysis on its effectiveness on the adherence to EBF practices at the end of 6 months as the primary outcome. The second specific objective included six other secondary outcomes which are complementary parameters in determining the effectiveness of breastfeeding or factors which significantly influence the primary outcome. They were: EBF at the end of 4 months, full formula-feeding within 2 months, support of the father, prevalence of breastfeeding related problems, knowledge of the mother on breastfeeding, and the attitudes of the mother on breastfeeding.

\section{Methods \\ Protocol and registration}

Preferred Reporting Items for Systematic Reviews and Meta-analyses (PRISMA) guidelines were referred [40]. The review was registered in the PROSPERO-International prospective register of systematic reviews registration (2017-CRD42017076163). Subsequent amendments were made in the protocol clarifying the eligibility criteria further.

\section{Eligibility criteria}

The research question was composed based on PICOS and SPIDER sequence [41]. It was formulated as "targeting the father/male-partner in addition, more effective than targeting the pregnant or new mother alone, in promoting breastfeeding with evidences of interventional studies." 
The criteria for the selection of studies included: being a randomized or quasi experimental study, the intervention group including the male partners, and the intervention being delivered either in the antenatal period and/or within the postnatal period.

\section{Search strategy}

The PubMed, EMBASE, Google Scholar and CENTRAL-Cochrane library were searched. Our search strategy was 'breastfeeding' AND 'expectant father OR father OR male partner.' By contacting the fellow colleagues of the related fields, attempts were made to seek any unpublished literature. Furthermore reference lists of the selected articles and references of the systematic reviews were carefully studied in tracing the eligible articles.

\section{Selection of studies}

The selection of the studies was done in three rounds. In the first round, original research articles, which were compatible with the general objective of the present review, were selected. In the second round, articles on experimental studies were retained. In the third round, the studies which are compatible with the specific objectives were retained. In the first and second rounds, when the selection could not be done by the details mentioned in the abstracts, full articles were referred. Full articles were compulsorily referred in the third round.

The selection of articles was done by two independent reviewers. It was ensured that in selected articles, the intervention had been specifically targeting breastfeeding promotion. The articles which were selected by both reviewers were identified first. When there was a disparity, a third reviewer was involved to resolve it following a discussion with original reviewers. Following de-duplication, 410 articles were selected to be screened (Fig. 1).

\section{Data-extraction}

Data extraction was done by two reviewers independently using a pre-designed template. A third reviewer ensured the similarity of the two datasets of the initial reviewers. The extracted variables are summarized in Table 1.

\section{Estimation of bias}

The risk of bias table was composed based on the recommendations for the randomized trials and quasi experimental studies [42-47]. The bias assessment was based on the methodological issues related to random number generation, allocation concealment, performance bias, detection bias, attrition bias, reporting bias, and any other bias. Determination of the level of bias

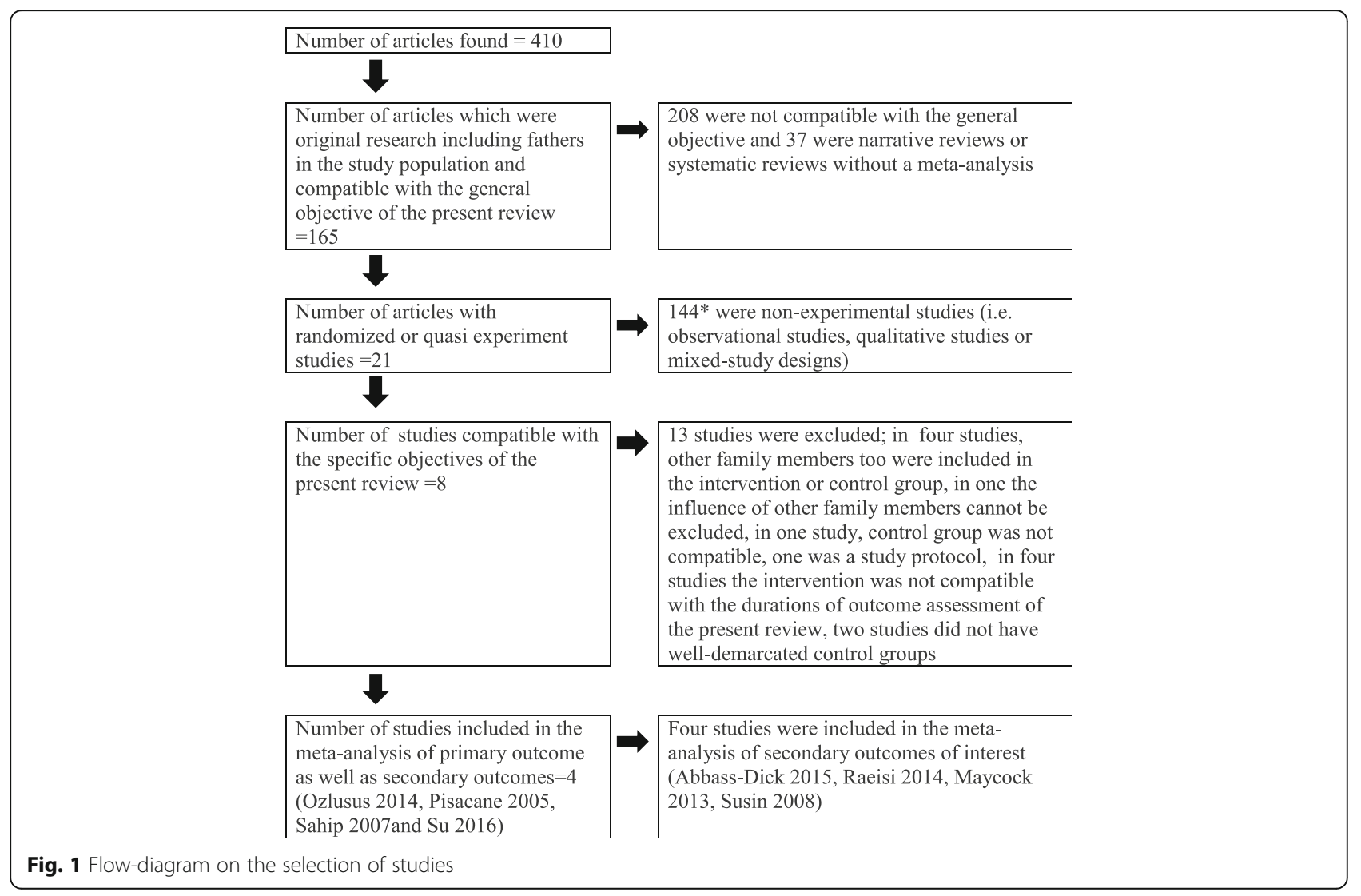


Table 1 Extracted variables from selected studies

\begin{tabular}{|c|c|c|c|c|}
\hline Population & Intervention & Comparison & Outcome & Study design \\
\hline $\begin{array}{l}\text {-Eligibility criteria } \\
\text {-Characteristics of the participants }\end{array}$ & $\begin{array}{l}\text {-Kind of intervention/s } \\
\text { done with duration/s }\end{array}$ & $\begin{array}{l}\text {-Number of arms } \\
\text {-Number participated } \\
\text {-Number completed the } \\
\text { allocated exposure }\end{array}$ & $\begin{array}{l}\text {-Primary and secondary outcomes } \\
\text {-How the outcomes were measured } \\
\text {-Number of participants with each outcome }\end{array}$ & $\begin{array}{l}\text {-Type of design } \\
\text {-Year of conduct } \\
\text {-Study setting }\end{array}$ \\
\hline
\end{tabular}

was done by two reviewers independently and was contributed by a third reviewer in case of a disparity of decisions. Publication bias was assessed by a funnel plot [48].

\section{Meta-analysis and narrative synthesis}

The assessment for statistical heterogeneity of the selected studies was done with chi-square and I-square tests for all the meta-analyses [48, 49]. The cut-off of the I-square test for heterogeneity was considered as 50\% and for the $p$ value of chi-square test was considered as 0.1 [42, 48]. Meta-analysis was done by the software Review Manager (version 5.3) having done the heterogeneity assessments [50]. Mental- Haenszel method was used in pooling. Fixed-model assumptions were used in meta-analysis which was complemented by the randommodel assumptions in assessing the robustness of findings. Risk Ratio (RR) was used as the effect measure as it has been described as less-misleading compared to the Odds Ratio [51, 52]. Narrative synthesis was done when the selected studies were found be heterogeneous by both chi-square statistic and I-square values [53, 54]. Combined results were presented in a Summary of Findings (SoF) table (Table 2) [55]. The quality of evidence was assessed with the criteria of "Grading of Recommendations, Assessment, Development and Evaluations (GRADE) Working Group" with the help of the "GRADEproGDT" application [45-47].

\section{Assessing the robustness of the results}

The sensitivity analysis was done by re-performing the meta-analysis with random-model assumption following the initial fixed-model assumption [56, 57]. Furthermore, it was done by repeating the meta-analysis of the primary outcome leaving out one study at a time [58].

\section{Results}

\section{Selection of studies}

The selection-related details of the studies are summarized in Fig. 1. Twenty experimental studies were thus selected in the second round. Out of these twenty, thirteen studies were excluded in the third round [20, 59-70]. Out of the remaining eight studies, four were included in the meta-analysis of the primary as well as secondary outcomes of interest [71-74]. Four others were included in meta-analysis of the secondary outcomes [75-78]. All eight studies included
1852 families. During the search, only one article which gives the impression of an experimental study by the title, could not be traced [79].

\section{Interventions of the studies}

Interventions consisted of Information-EducationCommunication methodologies including; face-to-face discussions, power-point presentations, usage of brochures, usage of models, leaflets, and electronic media. In three studies (Su 2016, Sahip 2007, Raeisi 2014) the intervention was done during the antenatal period [73-75]. In two studies (Ozlusus 2014, Maycock 2013) the intervention started in the antenatal period and extended in to the neonatal period $[72,76]$. In three studies (Susin 2008, Pisacane 2005, Abbass-Dick 2015), the intervention was done in the neonatal period $[71,77,78]$.

\section{Results of bias assessment}

All eight studies were with low risks of attrition, reporting, and other biases. Blinding of participants was done only in the study of Piscane (2015). High-risk of bias due to issues related to random number generation and allocation concealment could not be excluded respectively in four and five studies (Fig. 2).

\section{Meta-analysis of the primary outcome}

Four studies were selected for the meta-analysis for the first specific objective (i.e. primary outcome) (Table 3). This meta-analysis included 587 families with 294 in the experimental group (i.e. the male partner involved in the health education) and 293 in the control group (male partner not involved in the health education). The four selected studies seemingly were not significantly heterogeneous $\left(\mathrm{I}^{2}=0 \%, p\right.$ value $\left.=0.46\right)$. The pooled $\mathrm{RR}$ was $2.04(\mathrm{CI}=1.58$ to 2.65$)$. It reflects that compared to a baby whose father has not participated in a breastfeeding promotional intervention, a baby whose father attended such an intervention is more than two times as likely to be exclusively breastfed for 6 months (Fig. 3).

The effect measures of the selected studies yielded an approximately symmetrical Funnel-plot as shown in Fig. 4.

The results of the sensitivity analysis have been mentioned in Table 4. Even when the meta-analysis was done with random-model assumption as well as when it was repeated removing one study at a time, the pooled estimates were significantly favoring the interventional groups. 

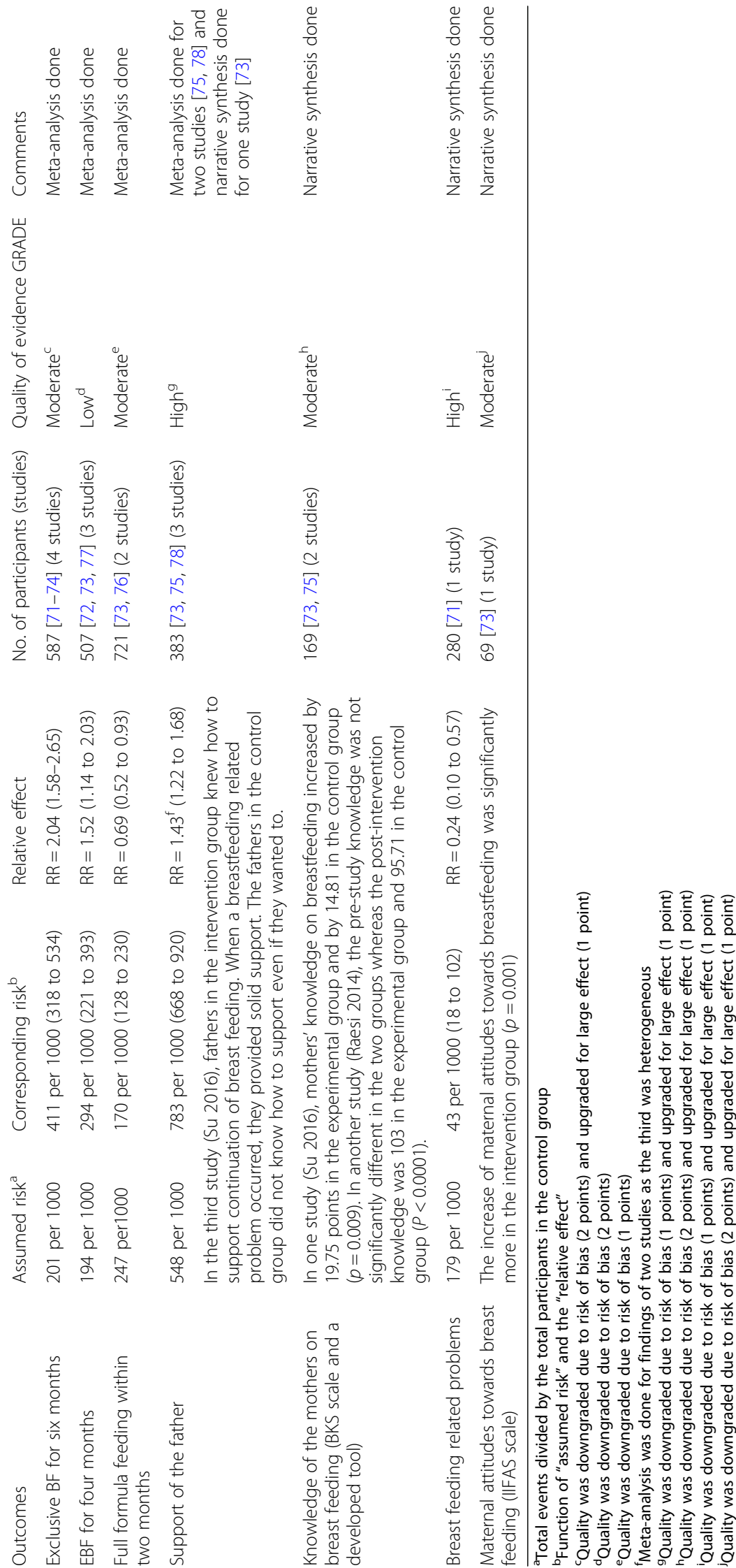


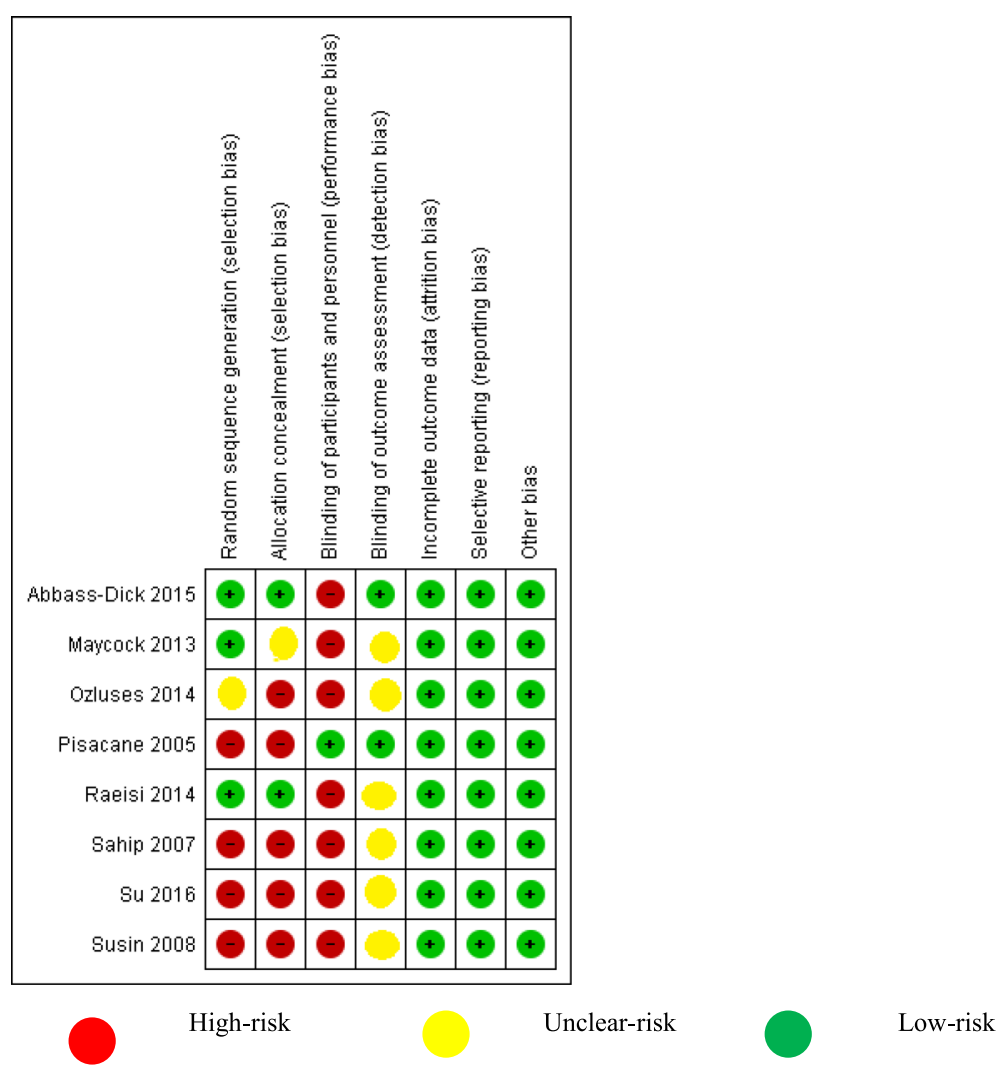

Fig. 2 Risk of bias summary of individual studies

\section{Meta-analysis and narrative synthesis of the secondary outcomes}

The characteristics of the selected studies for the analysis of secondary outcomes have been summarized in Table 5. The SOF table was prepared for the seven outcomes (Table 2). For four outcomes (EBF at the end of 6 months, EBF at the end of 4 months, full formula feeding within 2 months and support of the father), meta-analysis showed favorable outcomes in the interventional groups than in the control groups. Respectively, the chi-square values and I-square values in the heterogeneity analysis for EBF at the end of 4 months were 0.62 and $0 \%$. For formula feeding within 2 months the respective values were 0.13 and 55\%. For the support of father, they were 0.37 and $0 \%$, respectively.

The first three-pooled measures were found to be robust with sensitivity analysis done by repeating with random-model assumption. The effect measure for the "support of the father" became non-significant when the latter model-assumption was used. The occurrence of breastfeeding problems showed a very lower likelihood in the intervention group. The narrative summaries for knowledge of mother on breastfeeding, maternal attitudes towards breastfeeding and the additional narrative summary for the support of father, too demonstrated favorable outcomes in the intervention groups than in the control groups. 


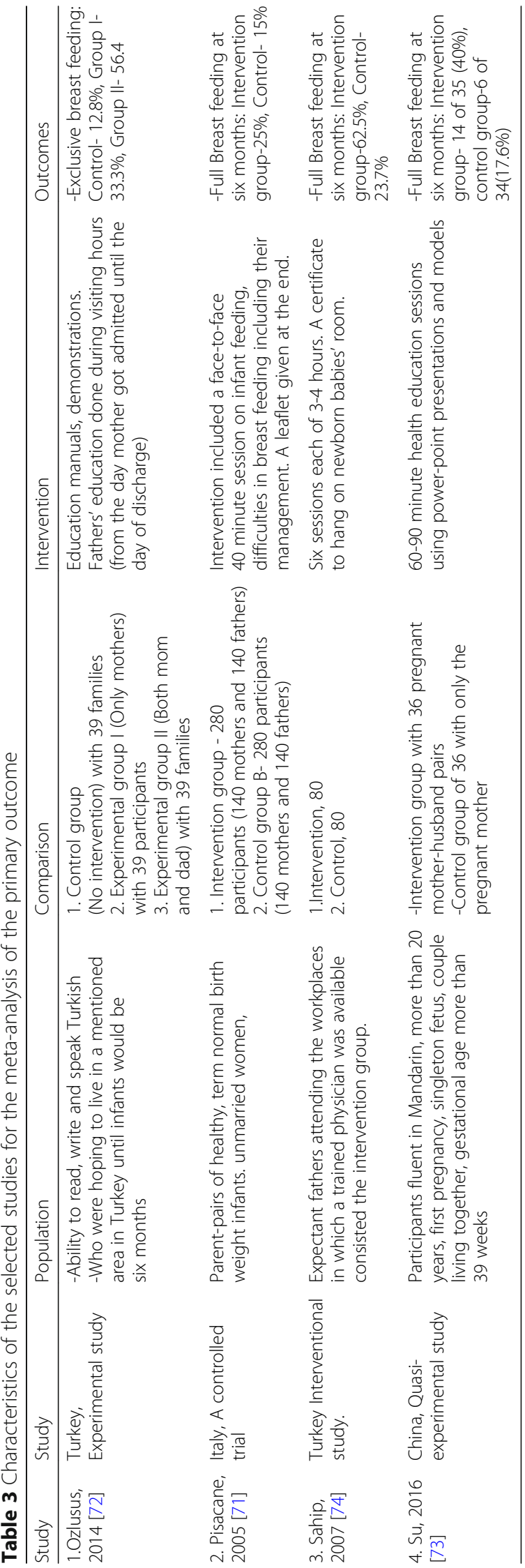




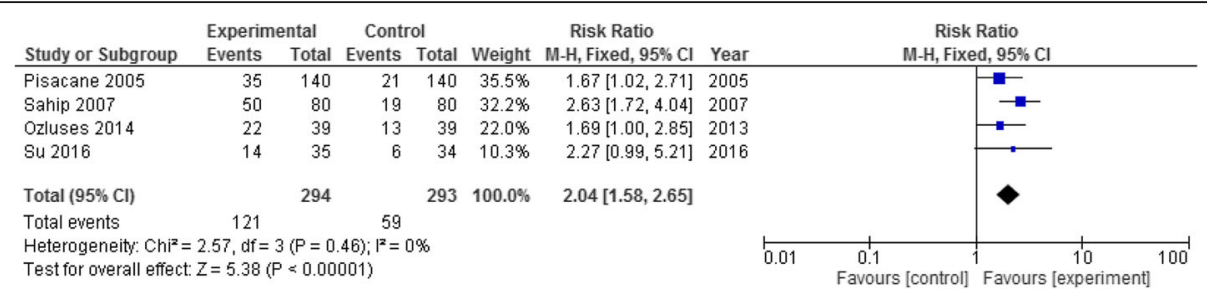

Fig. 3 Forest-plot with fixed-model assumption for the primary outcome

The quality of evidence was determined as: low (for one outcome), moderate (for two outcomes), and high (for two outcomes) based on the recommendations of GRADE recommendations.

\section{Discussion}

This is the first systematic review with a meta-analysis of the effectiveness of targeting the male partner for the promotion of breastfeeding. The meta-analysis revealed that targeting the fathers is associated with two times the likelihood of getting the baby exclusively breastfed for 6 months. Furthermore, the experimental groups achieved favorable results when the other six outcomes were concerned as well. The systematic review included both randomized controlled trials as well as quasiexperimental trials. The suitability of the inclusion of the latter in systematic reviews have been highlighted in modern literature [80].

The quality of this systematic review and metaanalysis was ensured with several steps. Firstly, the data search was done without restricting to a time period. It is mentioned that searching all available data as a better strategy in systematic reviews [81]. The duration of EBF was recommended to be 6 months from the beginning of twenty-first century and until then, there had been a debate about shorter duration [82, 83]. Many of the previously documented literature had no uniformity of considering EBF period as 6 months [84]. Since then it was decided to include another secondary outcome for a shorter duration (i.e. EBF for 4 months).

Risk of bias estimates were not done by averaging the several components of the bias estimates but by utilizing recommended guidelines. [42, 45, 85] Not surprisingly, in the majority of studies, blinding had not been possible and as a result they were categorized as high-risk for the performance bias. Strict categorizing criteria were adhered to in the estimation of bias. As an example, when the allocations were done based on time period of delivery of baby, the high-risk categorization for selection bias was given and down-grading was done in determining the quality of evidence in the SoF table. To improve the validity of the results, RR was used as the effect measure instead of odds ratio $[51,52]$.

It is recommended to consider the statistical, clinical, and methodological heterogeneity in interpreting the quality of meta-analysis $[48,86,87]$. The statistical heterogeneity of the studies were seemingly acceptable based on I-square percentages and chi-square values $[42,48-50]$. Only the I-square value was marginally high for one of the secondary outcomes (i.e. for the

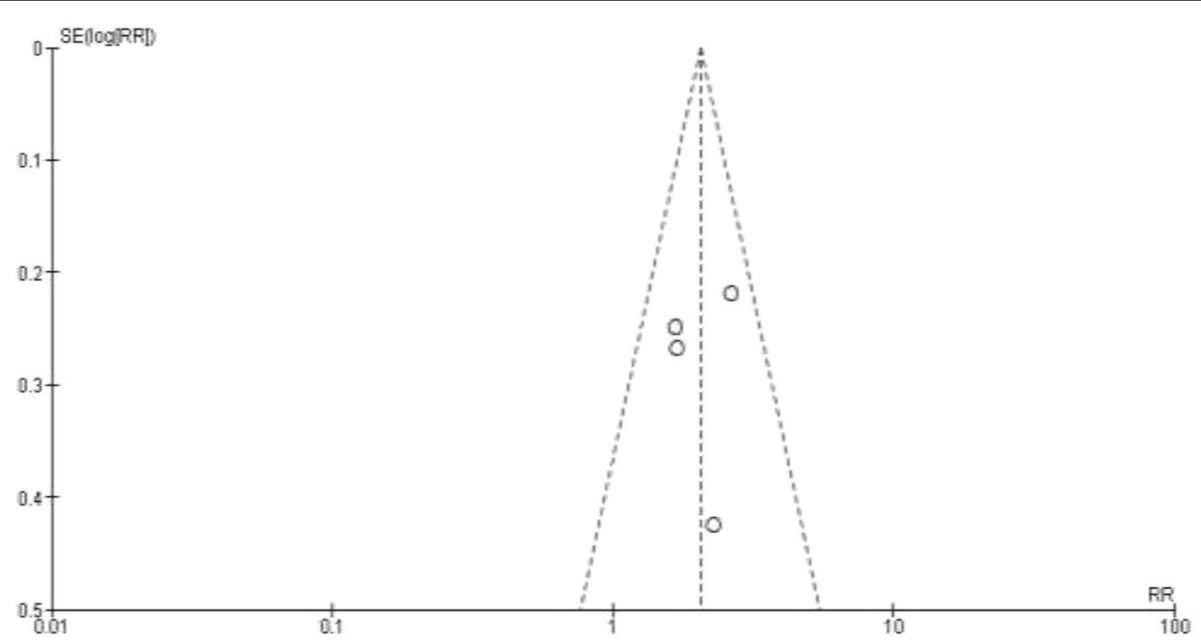

Fig. 4 Funnel plot of the studies used in meta-analysis of the primary outcome 
Table 4 Sensitivity and sub group analysis of the pooled estimate of primary outcome

\begin{tabular}{|c|c|c|c|c|}
\hline & Heterogeneity & Number & Risk Ratio & Confidence Interval \\
\hline With fixed-model assumption (four studies) & $\begin{array}{l}I^{2} \text { value- } 0 \% \\
P=0.46\end{array}$ & 587 & 2.04 & 1.58 to 2.65 \\
\hline With random-model assumption (four studies) & $\begin{array}{l}I^{2} \text { value- } 0 \% \\
P=0.46\end{array}$ & 587 & 2.04 & 1.57 to 2.65 \\
\hline Fixed-model assumption with Ozlusus 2014 removed & $\begin{array}{l}I^{2} \text { value- } 0 \% \\
P=0.38\end{array}$ & 509 & 2.14 & 1.59 to 2.89 \\
\hline Random-model assumption with Ozlusus 2014 removed & $\begin{array}{l}I^{2} \text { value- } 0 \% \\
P=0.38\end{array}$ & 509 & 2.17 & 1.61 to 2.93 \\
\hline Fixed-model assumption with Pisacane 2005 removed & $\begin{array}{l}I^{2} \text { value- } 0 \% \\
P=0.44\end{array}$ & 307 & 2.25 & 1.66 to 3.07 \\
\hline Random-model assumption with Pisacane 2005 removed & $\begin{array}{l}I^{2} \text { value- } 0 \% \\
P=0.44\end{array}$ & 307 & 2.21 & 1.63 to 3.01 \\
\hline Fixed-model assumption with Sahip 2007 removed & $\begin{array}{l}I^{2} \text { value- } 0 \% \\
P=0.81\end{array}$ & 427 & 1.77 & 1.27 to 2.46 \\
\hline Random-model assumption with Sahip 2007 removed & $\begin{array}{l}I^{2} \text { value- } 20 \% \\
P=0.29\end{array}$ & 427 & 1.76 & 1.27 to 2.44 \\
\hline Fixed-model assumption with Su 2016 removed & $\begin{array}{l}I^{2} \text { value- } 0 \% \\
P=0.29\end{array}$ & 518 & 2.02 & 1.53 to 2.66 \\
\hline Random-model assumption with Su 2016 removed & $\begin{array}{l}I^{2} \text { value- } 0 \% \\
P=0.29\end{array}$ & 518 & 2.00 & 1.47 to 2.73 \\
\hline
\end{tabular}

support of father). Clinical heterogeneity does not seemingly influence the results as most of the outcomes for which the meta-analyses were done are objectively categorically coded (as an example, whether EBF continued for 6 months or not). In all studies, the periods of interventions did not extend beyond the neonatal period. All outcome measurements had been done after 2 months of the birth. Measures to minimize methodological-bias were adhered to in selection of the studies and in the expression of risk of bias of each study. Furthermore, the control groups of the studies had been recruited from similar settings. Even though "fatherhood" is influenced by the culture, universally, fathers care for the well-being of the family and children $[88,89]$. Hence, though the degree of involvement of a father may vary in nutrition related affairs of the newborn, its direction in all settings can be assumed as towards getting more benefits to the baby.

An extensive sensitivity analysis has been done in the present manuscript. Sensitivity analysis has been defined as "a method to determine the robustness of an assessment by examining the extent to which results are affected by changes in methods, models, values of unmeasured variables, or assumptions." [90] Since all the measures except one in the sensitivity analysis point towards significant favorable effects of targeting fathers, the robustness of the conclusions become high.

Targeting fathers was effective in increasing likelihood of EBF at the end of 6 months as well as at the end of 4 months. RR for the EBF at 6 months is higher than that of the figure at 4 months and double as compared to the control group. In other words, it is associated with a higher probability of uninterrupted provision of breast milk enabling the child to get its benefits [1-6]. This finding can be evaluated further using the fourth outcome in the SoF table which is the support extended by the father for breastfeeding. High quality evidence was seen in the meta-analysis as well as the narrative synthesis showing the favorable influence of targeting fathers on the prospective support they render. When fathers get to know the scientific evidence on the benefits of breastfeeding, it can be postulated that they would encourage the partner to continue this course. This would have resulted in increasing their support as well as indirectly prolonging the duration of EBF.

The prevalence of full-formula-feeding was less in the intervention group. This finding can be discussed coupling to the sixth outcome (i.e. occurrence of breastfeeding related problems). When fathers are educated on breastfeeding, due to their support (i.e. fourth outcome), better positioning and attachment of the baby to the breast during feeding would be facilitated. Lesser lactation-related problems would ensure not opting for the formula milk. Furthermore, this would be facilitated by the fact that mothers' knowledge and attitudes on breastfeeding becoming more favorable with the intervention (i.e. fifth and seventh outcomes).

The effect of the intervention on mothers' knowledge and on favorable attitudes can be described with several explanations. The mutual discussions that occur in the household with the partners would improve mothers' 


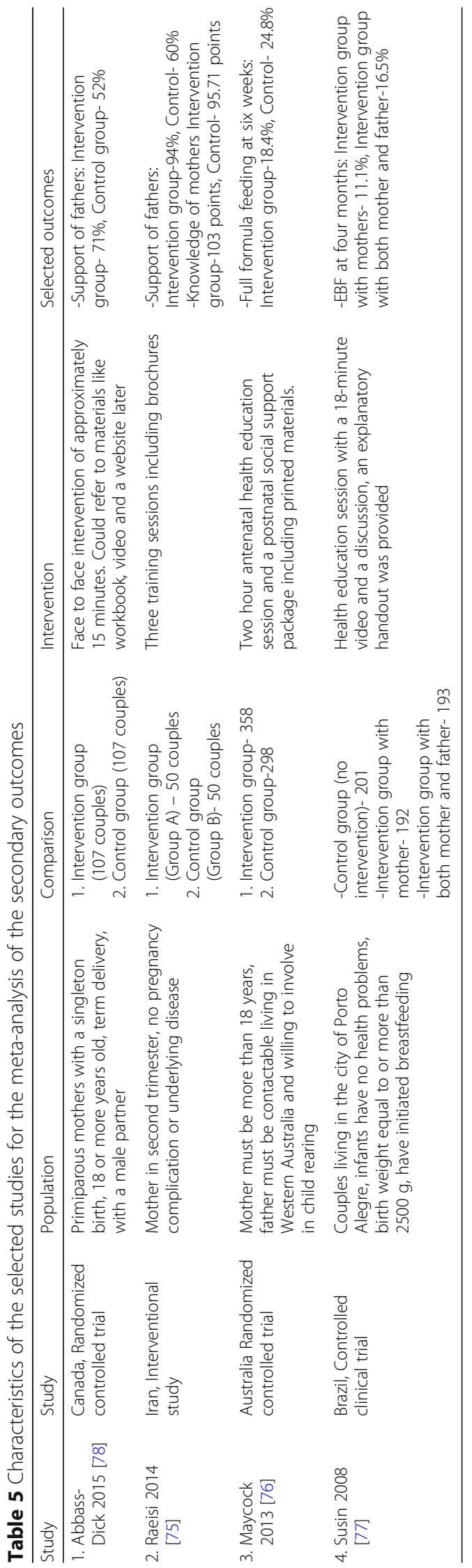


knowledge. Secondly, the positive perception of the partner's attitude on breastfeeding would foster the mothers' attitudes as well. This is compatible with the global literature [27].

In the present review, all seven outcomes, including EBF rates, were favorably influenced by targeting the expectant fathers for promotion of breast milk. This review adds value to the attempts made by the healthcare systems in involving expectant and new fathers in the interventions for the promotion of breastfeeding. More emphasis could be given for the male-partner domain of the awareness packages that are done in the ante-natal and neonatal periods for the promotion of breastfeeding. Since the breastfeeding is associated with mitigation of communicable diseases as well as prospective occurrence of NCDs, targeting fathers becomes a cost-effective strategy which yields the effects through prolonged duration of EBF. Breastfeeding related indicators are used to determine the improvement of the health status of a country [91]. Furthermore, longer duration of breastfeeding is recommended as a "smart investment" in achieving Sustainable Developmental Goals [92]. Hence the intervention of this review would ensure better placement of countries in relation to health indicators.

There were several limitations of the review. Firstly, the results could not be standardized for the quality of the interventions. This was because the review was done on different experimental studies which were done on different settings using different intervention packages. To compensate for its impact, seven outcome measures which are supposed to be linked with the awareness on general-aspects related to breastfeeding were selected. Furthermore in selecting the studies, special emphasis was given to the intervention-related details. Since the determination of the risk of bias and grading of the quality of evidence include judgmental decision-making, undue influence of being "subjective," could not be totally excluded. Yet, several steps like independent assessment by several reviewers, contacting the GRADE support group for clarifications were done. Another is that, in measuring the mothers' knowledge (fifth outcome), different tools were used. To minimize its impact, the narrative summary was made to focus on the "change of knowledge" rather than on the raw scores.

\section{Conclusions}

Targeting fathers in the antenatal and postnatal periods of the baby: improves EBF at 6 months $(\mathrm{RR}=2.04, \mathrm{CI}=$ $1.58-2.65)$ and $\mathrm{EBF}$ at 4 months $(\mathrm{RR}=1.52, \mathrm{CI}=1.14$ to 2.03). In addition it decreases the probability of fullformula-feeding at 2 months ( $\mathrm{RR}=0.69, \mathrm{CI}=0.52$ to 0.93 ) and the occurrence of breastfeeding related problems (RR $=0.24, \mathrm{CI}=0.10$ to 0.57 ). Furthermore it increases the support extended by the father in breastfeeding related issues $(\mathrm{RR}=1.43, \mathrm{CI}=1.22$ to 1.68$)$. Mothers' knowledge on breastfeeding and the favorable attitudes on breastfeeding are augmented with the intervention done on fathers $(P \leq ; 0.001)$.

The conclusions are robust as suggested by the sensitivity analysis. The quality of evidence ranges from "low" to "high" for different outcomes.

\section{Acknowledgements \\ Authors like to acknowledge Nicola Richards of Melbourne School of Global and Population Health, University of Melbourne for her valuable inputs in revising the manuscript.}

\section{Funding}

The review was self-funded and was not funded by a third party.

\section{Availability of data and materials}

The datasets used and/or analyzed during the review are available from the corresponding author on reasonable request.

\section{Authors' contributions}

PKBM was involved in the conceptualization of the review, literature search, data extraction, data analysis and drafting of the initial manuscript. MW, SM and $\mathrm{C}$ were involved in the conceptualization of the review, literature search, data extraction, data analysis and editing the manuscript. S, MFM and PM were involved in conceptualization of the review, literature search, data extraction, and editing the manuscript. SJ involved in revising of the manuscript. All authors read the final manuscript.

Ethics approval and consent to participate Not applicable.

\section{Consent for publication}

Not applicable.

\section{Competing interests}

The authors declare that they have no competing interests.

\section{Publisher's Note}

Springer Nature remains neutral with regard to jurisdictional claims in published maps and institutional affiliations.

\section{Author details}

'Office of Regional Director of Health Services, Colombo, Sri Lanka. ${ }^{2}$ Department of Community Medicine, Faculty of Medicine, University of Colombo, Colombo, Sri Lanka. ${ }^{3}$ Epidemiology Unit, Colombo, Sri Lanka. ${ }^{4}$ Faculty of Medicine, University of Colombo, Colombo, Sri Lanka. ${ }^{5}$ Ministry of Health, Colombo, Sri Lanka. ${ }^{6}$ Post Graduate Institute of Medicine, Colombo, Sri Lanka.

Received: 3 August 2018 Accepted: 13 September 2018 Published online: 24 September 2018

References

1. Motee A, Ramasawmy D, Pugo-Gunsam P, Jeewon R. An assessment of the breastfeeding practices and infant feeding pattern among mothers in Mauritius. J Nutr Metab. 2013;2013:1-8. https://doi.org/10.1155/2013/243852.

2. Kuchenbecker J, Jordan I, Reinbott A, et al. Exclusive breastfeeding and its effect on growth of Malawian infants: results from a cross-sectional study. Paediatr Int Child Health. 2015;35(1):14-23. https://doi.org/10.1179/ 2046905514 Y.0000000134.

3. Ogunrinade SA. Effects of exclusive breastfeeding on babies health in Ife Central local government of Osun State. Int J Nutr Metab. 2014;6(1):1-8. https://doi.org/10.5897/IJNAM2013.0156.

4. Walker WA, Shuba IR. Breastmilk, microbiota and intestinal immune homeostasis. Pediatr Res. 2014. https://doi.org/10.1038/pr.2014.160. 
5. Motee A, Jeewon R. Importance of Exclusive Breastfeeding and Complementary Feeding among Infants. Curr Res Nutr Food Sci J. 2014;2(2): 56-72. https://doi.org/10.12944/CRNFSJ.2.2.02.

6. Victora CG, Bahl R, Barros AJD, et al. Breastfeeding in the 21st century: epidemiology, mechanisms, and lifelong effect. Lancet. 2016;387(10017): 475-90. https://doi.org/10.1016/S0140-6736(15)01024-7.

7. Wojcicki JM, Heyman MB, Elwan D, Lin J, Blackburn E, Epel E. Early exclusive breastfeeding is associated with longer telomeres in Latino preschool children. Am J Clin Nutr. 2016;104(2):397-405. https://doi.org/10.3945/ajcn. 115.115428 .

8. Singhal A. The role of infant nutrition in the global epidemic of noncommunicable disease. Proc Nutr Soc. 2016;75(02):162-8. https://doi.org/10. 1017/S0029665116000057.

9. Kelishadi R, Farajian S. The protective effects of breastfeeding on chronic non-communicable diseases in adulthood: a review of evidence. Adv Biomed Res. 2014;3(1):3. https://doi.org/10.4103/2277-9175.124629.

10. Mahesh PKB, Gunathunga MW, Jayasinghe $S$, et al. Financial burden of survivors of medically-managed myocardial infarction and its association with selected social determinants and quality of life in a lower middle income country. BMC Cardiovasc Disord. 2017;17(1):251. https://doi.org/10. 1186/s12872-017-0687-y.

11. Mahesh PKB, Gunathunga MW, Jayasinghe S, Arnold SM, Liyanage SN. Factors influencing pre-stroke and post-stroke quality of life among stroke survivors in a lower middle-income country. Neurol Sci. 2018;39(2):287-95. https://doi.org/10.1007/s10072-017-3172-6.

12. World Health Organization. Infant and Young Child Feeding. http://www. who.int/mediacentre/factsheets/fs342/en/. Published 2017.

Accessed Nov 92017.

13. Cai $X$, Wardlaw T, Brown DW. Global trends in exclusive breastfeeding. Int Breastfeed J. 2012;7(1):12. https://doi.org/10.1186/1746-4358-7-12.

14. Heymann J, Raub A, Earle A. Breastfeeding policy: a globally comparative analysis. Bull World Health Organ. 2013;91(6):398-406. https://doi.org/10. 2471/BLT.12.109363.

15. Smith HA, Becker GE. Early additional food and fluids for healthy breastfed full-term infants. In: Smith HA, editor. Cochrane Database of Systematic Reviews. Chichester: John Wiley \& Sons, Ltd; 2016. https://doi.org/10.1002/ 14651858.CD006462.pub4.

16. Kramer MS, Kakuma R. Optimal duration of exclusive breastfeeding. In: Kramer MS, editor. Cochrane Database of Systematic Reviews. Chichester: John Wiley \& Sons, Ltd; 2012. https://doi.org/10.1002/14651858.CD003517.pub2.

17. Rollins NC, Bhandari N, Hajeebhoy N, et al. Why invest, and what it will take to improve breastfeeding practices? Lancet. 2016;387(10017):491-504. https://doi.org/10.1016/S0140-6736(15)01044-2.

18. Abbass-Dick J, Dennis C-L. Breast-feeding Coparenting framework. Fam Community Health. 2017;40(1):28-31. https://doi.org/10.1097/FCH. 0000000000000137.

19. Doğa Öcal F, Vural Yılmaz Z, Ceyhan M, Fadıl Kara O, Küçüközkan T. Early initiation and exclusive breastfeeding: factors influencing the attitudes of mothers who gave birth in a baby-friendly hospital. J Turkish Soc Obstet Gynecol. 2017:1-9. https://doi.org/10.4274/tjod.90018.

20. Susiloretni KA, Hadi H, Prabandari YS, Soenarto YS, Wilopo SA. What works to improve duration of exclusive breastfeeding: lessons from the exclusive breastfeeding promotion program in rural Indonesia. Matern Child Health J. 2015;19(7):1515-25. https://doi.org/10.1007/s10995-014-1656-z.

21. Garbarino F, Morniroli D, Ghirardi B, et al. Prevalence and duration of breastfeeding during the first six months of life: factors affecting an early cessation. La Pediatr Medica e Chir. 2013;35(5). https://doi.org/10.4081/pmc.2013.30.

22. Swigart TM, Bonvecchio A, Théodore FL, Zamudio-Haas S, VillanuevaBorbolla MA, Thrasher JF. Breastfeeding practices, beliefs, and social norms in low-resource communities in Mexico: Insights for how to improve future promotion strategies. van Wouwe JP, ed. PLoS One. 2017;12(7):e0180185. doi:https://doi.org/10.1371/journal.pone.0180185.

23. Brown A, Davies R. Fathers' experiences of supporting breastfeeding: challenges for breastfeeding promotion and education. Matern Child Nutr 2014;10(4):510-26. https://doi.org/10.1111/mcn.12129.

24. Rempel LA, Rempel JK. The breastfeeding team: the role of involved fathers in the breastfeeding family. J Hum Lact. 2011;27(2):115-21. https://doi.org/ 10.1177/0890334410390045.

25. Bennett AE, McCartney D, Kearney JM. Views of fathers in Ireland on the experience and challenges of having a breast-feeding partner. Midwifery. 2016:40:169-76. https://doi.org/10.1016/j.midw.2016.07.004
26. Hunter T, Cattelona G. Ann. Breastfeeding initiation and duration in firsttime mothers: exploring the impact of father involvement in the early postpartum period. Heal Promot Perspect. 2014;4(2):132-6. https://doi.org/10. 5681/hpp.2014.017.

27. Zhu J, Chan WCS, Zhou X, Ye B, He H-G. Predictors of breast feeding selfefficacy among Chinese mothers: a cross-sectional questionnaire survey. Midwifery. 2014;30(6):705-11. https://doi.org/10.1016/j.midw.2013.12.008.

28. Yang $X$, Gao L, Ip W-Y, Sally Chan WC. Predictors of breast feeding selfefficacy in the immediate postpartum period: a cross-sectional study. Midwifery. 2016;41:1-8. https://doi.org/10.1016/j.midw.2016.07.011.

29. Robert E, Coppieters V, Swennen B, Dramaix M. Determinants of breastfeeding in the Brussels Region. Rev Med Brux. 36(2):69-74 http://www.ncbi.nlm.nih.gov/pubmed/26164964.

30. Yourkavitch JM, Alvey JL, Prosnitz DM, Thomas JC. Engaging men to promote and support exclusive breastfeeding: a descriptive review of 28 projects in 20 low- and middle-income countries from 2003 to 2013. J Health Popul Nutr. 2017;36(1):43. https://doi.org/10.1186/s41043-017-0127-8.

31. Emmott EH, Mace R. Practical support from fathers and grandmothers is associated with lower levels of breastfeeding in the UK Millennium Cohort Study. Raju T, ed. PLoS One. 2015;10(7):e0133547. doi:https://doi.org/10. 1371/journal.pone.0133547.

32. Karande S, Perkar S. Do fathers' attitudes support breastfeeding? A crosssectional questionnaire-based study in Mumbai, India. Indian J Med Sci. 2012;66(1):30. https://doi.org/10.4103/0019-5359.110861.

33. Balogun $\mathrm{OO}$, O'Sullivan EJ, McFadden A, et al. Interventions for promoting the initiation of breastfeeding. In: Balogun OO, editor. Cochrane Database of Systematic Reviews. Chichester: John Wiley \& Sons, Ltd; 2016. https://doi. org/10.1002/14651858.CD001688.pub3.

34. World Health Organization. Guideline: protecting, promoting and supporting breastfeeding in facilities providing maternity and newborn services. Geneva: World Health Organization; 2017.

35. Ganeshkumar P, Gopalakrishnan S. Systematic reviews and meta-analysis: understanding the best evidence in primary healthcare. J Fam Med Prim Care. 2013;2(1):9. https://doi.org/10.4103/2249-4863.109934.

36. Lumbiganon P, Martis R, Laopaiboon M, Festin MR, Ho JJ, Hakimi M. Antenatal breastfeeding education for increasing breastfeeding duration. In: Lumbiganon P, editor. Cochrane Database of Systematic Reviews. Chichester: John Wiley \& Sons, Ltd; 2011. https://doi.org/10.1002/14651858.CD006425.pub2.

37. Mitchell-Box KM, Braun KL. Impact of male-partner-focused interventions on breastfeeding initiation, exclusivity, and continuation. J Hum Lact. 2013; 29(4):473-9. https://doi.org/10.1177/0890334413491833.

38. Aussems M-CE, Boomsma A, Snijders TAB. The use of quasi-experiments in the social sciences: a content analysis. Qual Quant. 2011;45(1):21-42. https:// doi.org/10.1007/s11135-009-9281-4.

39. Harris AD, McGregor JC, Perencevich EN, et al. The use and interpretation of quasi-experimental studies in medical informatics. J Am Med Informatics Assoc. 2006;13(1):16-23. https://doi.org/10.1197/jamia.M1749.

40. Johansen M, Thomsen SF. Guidelines for reporting medical research: a critical appraisal. Int Sch Res Not. 2016;2016:1-7. https://doi.org/10.1155/ 2016/1346026.

41. Methley AM, Campbell S, Chew-Graham C, McNally R, Cheraghi-Sohi S. PICO, PICOS and SPIDER: a comparison study of specificity and sensitivity in three search tools for qualitative systematic reviews. BMC Health Serv Res. 2014;14(1):579. https://doi.org/10.1186/s12913-014-0579-0.

42. Conway A, Clarke MJ, Treweek S, et al. Summary of findings tables for communicating key findings of systematic reviews. In: Conway A, editor. Cochrane Database of Systematic Reviews. Chichester: John Wiley \& Sons, Ltd; 2017. https://doi.org/10.1002/14651858.MR000044.

43. Kim JH, Kim TK, In J, Lee DK, Lee S, Kang H. Assessment of risk of bias in quasi-randomized controlled trials and randomized controlled trials reported in the Korean journal of anesthesiology between 2010 and 2016. Korean J Anesthesiol. 2017;70(5):511. https://doi.org/10.4097/kjae.2017.70.5.511.

44. Waddington $\mathrm{H}$, Aloe AM, Becker BJ, et al. Quasi-experimental study designs series_paper 6: risk of bias assessment. J Clin Epidemiol. 2017:89:43-52. https://doi.org/10.1016/j.jclinepi.2017.02.015.

45. Guyatt $\mathrm{GH}$, Oxman AD, Vist $\mathrm{G}$, et al. GRADE guidelines: 4. Rating the quality of evidence—study limitations (risk of bias). J Clin Epidemiol. 2011;64(4): 407-15. https://doi.org/10.1016/j.jclinepi.2010.07.017.

46. GRADE working group. Grading quality of evidence and strength of recommendations. BMJ 2004:328(7454):1490-0. doi:https://doi.org/10.1136/ bmj.328.7454.1490 
47. Balshem $H$, Helfand $M$, Schünemann $H J$, et al. GRADE guidelines: 3. Rating the quality of evidence. J Clin Epidemiol. 2011;64(4):401-6. https://doi.org/ 10.1016/j.jclinepi.2010.07.015.

48. Bown MJ, Sutton AJ. Quality control in systematic reviews and metaanalyses. Eur J Vasc Endovasc Surg. 2010;40(5):669-77. https://doi.org/10. 1016/j.ejvs.2010.07.011.

49. Melsen WG, Bootsma MCJ, Rovers MM, Bonten MJM. The effects of clinical and statistical heterogeneity on the predictive values of results from metaanalyses. Clin Microbiol Infect. 2014;20(2):123-9. https://doi.org/10.1111/ 1469-0691.12494.

50. Israel H, Richter RR. A guide to understanding meta-analysis. J Orthop Sport Phys Ther. 2011;41(7):496-504. https://doi.org/10.2519/jospt.2011.3333.

51. Akobeng AK. Understanding systematic reviews and meta-analysis. Arch Dis Child. 2005;90(8):845-8. https://doi.org/10.1136/adc.2004.058230.

52. Schechtman E. Odds ratio, relative risk, absolute risk reduction, and the number needed to treat-which of these should we use? Value Heal. 2002; 5(5):431-6. https://doi.org/10.1046/J.1524-4733.2002.55150.x.

53. Campbell M, Thomson H, Katikireddi SV, Sowden A. Reporting of narrative synthesis in systematic reviews of public health interventions: a methodological assessment. Lancet. 2016;388:S34. https://doi.org/10.1016/ S0140-6736(16)32270-X.

54. Snilstveit B, Oliver S, Vojtkova M. Narrative approaches to systematic review and synthesis of evidence for international development policy and practice. J Dev Eff. 2012;4(3):409-29. https://doi.org/10.1080/19439342.2012.710641.

55. Langendam MW, Akl EA, Dahm P, Glasziou P, Guyatt G, Schünemann HJ. Assessing and presenting summaries of evidence in Cochrane reviews. Syst Rev. 2013;2(1):81. https://doi.org/10.1186/2046-4053-2-81.

56. Schroll JB, Moustgaard R, Gøtzsche PC. Dealing with substantial heterogeneity in Cochrane reviews. Cross-sectional study. BMC Med Res Methodol. 2011;11(1):22. https://doi.org/10.1186/1471-2288-11-22.

57. Brugha TS, Matthews R, Morgan Z, Hill T, Alonso J, Jones DR. Methodology and reporting of systematic reviews and meta-analyses of observational studies in psychiatric epidemiology: systematic review. Br J Psychiatry. 2012; 200(6):446-53. https://doi.org/10.1192/bjp.bp.111.098103.

58. Wang Z-Y, Zhao K, Zheng J, et al. Systematic review and meta-analysis of the association between complement factor $\mathrm{H} 162 \mathrm{~V}$ polymorphism and risk of polypoidal choroidal vasculopathy in Asian populations. Anderson MG. PLoS One. 2014;9(2):e88324. doi:https://doi.org/10.1371/journal.pone. 0088324.

59. Wolfberg AJ, Michels KB, Shields W, O'Campo P, Bronner Y, Bienstock J. Dads as breastfeeding advocates: results from a randomized controlled trial of an educational intervention. Am J Obstet Gynecol. 2004;191(3):708-12. https://doi.org/10.1016/j.ajog.2004.05.019.

60. Maycock BR, Scott JA, Hauck YL, et al. A study to prolong breastfeeding duration: design and rationale of the parent infant feeding initiative (PIFI) randomised controlled trial. BMC Pregnancy Childbirth. 2015;15(1):159 https://doi.org/10.1186/s12884-015-0601-5.

61. Hannula LS, Kaunonen ME, Puukka PJ. A study to promote breast feeding in the Helsinki metropolitan area in Finland. Midwifery. 2014;30(6):696-704 https://doi.org/10.1016/j.midw.2013.10.005.

62. Susiloretni KA, Krisnamurni S, Sunarto, WEidiyanto SYD, Yazid A, Wilopo SA The effectiveness of multilevel promotion of exclusive breastfeeding in rural Indonesia. Am J Health Promot. 2013;28(2):e44-55. https://doi.org/10.4278/ ajhp.120425-QUAN-221.

63. Wockel A, Abou-Dakn M. Influence of the partner on breastfeeding duration and breast diseases during lactation. Results of an intervention study. Gynakol Prax. 2009;33(4):643-9.

64. Bich TH, Hoa DTP, Ha NT, Vui LT, Nghia DT, Målqvist M. Father's involvement and its effect on early breastfeeding practices in Viet Nam. Matern Child Nutr. 2016;12(4):768-77. https://doi.org/10.1111/mcn.12207.

65. Furman L, Killpack S, Matthews L, Davis V, O'Riordan MA. Engaging InnerCity fathers in breastfeeding support. Breastfeed Med. 2016;11(1):15-20. https://doi.org/10.1089/bfm.2015.0092.

66. Tohotoa J, Maycock B, Hauck Y, Howat P, Burns S, Binns C. Supporting mothers to breastfeed: the development and process evaluation of a father inclusive perinatal education support program in Perth, Western Australia. Health Promot Int. 2011;26(3):351-61. https://doi.org/10.1093/ heapro/daq077.

67. Ingram J, Johnson D. A feasibility study of an intervention to enhance family support for breast feeding in a deprived area in Bristol, UK. Midwifery. 2004;20(4):367-79. https://doi.org/10.1016/j.midw.2004.04.003.
68. Stremler J, Lovera D. Insight from a breastfeeding peer support pilot program for husbands and fathers of Texas WIC participants. J Hum Lact. 2004;20(4):417-22. https://doi.org/10.1177/0890334404267182.

69. Susin LR, Giugliani ER, Kummer SC, Maciel M, Simon C, da Silveira LC. Does parental breastfeeding knowledge increase breastfeeding rates? Birth. 1999; 26(3):149-56.

70. Bich TH, Hoa DTP, Målqvist M. Fathers as supporters for improved exclusive breastfeeding in Viet Nam. Matern Child Health J. 2014;18(6):1444-53. https://doi.org/10.1007/s10995-013-1384-9.

71. Pisacane A. A controlled trial of the Father's role in breastfeeding promotion. Pediatrics. 2005;116(4):e494-8. https://doi.org/10.1542/peds. 2005-0479.

72. Özlüses $E$, Çelebioglu A. Educating fathers to improve breastfeeding rates and paternal-infant attachment. Indian Pediatr. 2014;51(8):654-7. https://doi.org/10.1007/s13312-014-0471-3.

73. Su M, Ouyang Y-Q. Father's role in breastfeeding promotion: lessons from a quasi-experimental trial in China. Breastfeed Med. 2016;11(3):144-9. https://doi.org/10.1089/bfm.2015.0144.

74. SAHIP Y, Molzan Turan J. education for expectant fathers in workplaces in Turkey. J Biosoc Sci. 2007;39(06). https://doi.org/10.1017/S0021932007002088.

75. Raeisi K, Shariat M, Nayeri F, Raji F, Dalili H. A single center study of the effects of trained fathers' participation in constant breastfeeding. Acta Med Iran. 2014;52(9):694-6.

76. Maycock B, Binns CW, Dhaliwal S, et al. Education and support for fathers improves breastfeeding rates. J Hum Lact. 2013;29(4):484-90. https://doi.org/ 10.1177/0890334413484387.

77. Rosane Odeh Susin L, Regina Justo Giugliani E. Inclusion of fathers in an intervention to promote breastfeeding: impact on breastfeeding rates. J Hum Lact. 2008;24(4):386-92. https://doi.org/10.1177/0890334408323545.

78. Abbass-Dick J, Stern SB, Nelson LE, Watson W, Dennis C-L. Coparenting breastfeeding support and exclusive breastfeeding: a randomized controlled trial. Pediatrics. 2015;135(1):102-10. https://doi.org/10.1542/peds.2014-1416

79. Suomela A, Verronen $P$, Tamminen $T$, Nurmi $R$, Turunen $L$. The father, a very important figure if breast feeding is to succeed. A successful Tampere project. Katilolehti. 1982:87(11):332-9.

80. Rockers PC, Tugwell P, Grimshaw J, et al. Quasi-experimental study designs series-paper 12: strengthening global capacity for evidence synthesis of quasi-experimental health systems research. J Clin Epidemiol. 2017;89:98-105. https://doi.org/10.1016/j.jclinepi.2016.03.034.

81. Meehan S, Beck CR, Mair-Jenkins J, Leonardi-Bee J, Puleston R. Maternal obesity and infant mortality: a meta-analysis. Pediatrics. 2014;133(5):863-71. https://doi.org/10.1542/peds.2013-1480.

82. Dewey K. Guiding principles for complementary feeding of the breastfed (PAHO and WHO). Pan Am Heal Organ World Heal Organ. 2001:18-25. https://doi.org/10.1017/S1368980011002485.

83. Kramer MS, Kakuma R. The optimal duration of exclusive breastfeeding: a systematic review. World Heal Organ. 2001;47. https://doi.org/10.1002/ 14651858.CD003517.

84. Sciacca JP, Dube DA, Phipps BL, Ratliff MI. A breast feeding education and promotion program: effects on knowledge, attitudes, and support for breast feeding. J Community Health. 1995;20(6):473-90.

85. Higgins JPT, Green S, ed. Cochrane Handbook for Systematic Reviews of Interventions Version 5.1.0 [Updated March 2011]. The Cochrane Collaboration; 2011.

86. West SL, Gartlehner G, Mansfield AJ, et al. Comparative Effectiveness Review Methods: Clinical Heterogeneity. Agency Healthc Res Qual. 2010. Methods Research Paper. AHRQ Publication No. 10-EHC070-EF. http://effectivehealthcare.ahrq.gov/.

87. Gagnier JJ, Moher D, Boon H, Beyene J, Bombardier C. Investigating clinical heterogeneity in systematic reviews: a methodologic review of guidance in the literature. BMC Med Res Methodol. 2012;12(1):111. https://doi.org/10. 1186/1471-2288-12-111.

88. Cruz RA, King KM, Widaman KF, Leu J, Cauce AM, Conger RD. Cultural influences on positive father involvement in two-parent Mexican-origin families. J Fam Psychol. 2011;25(5):731-40. https://doi.org/10.1037/a0025128.

89. Roopnarine $\mathrm{J}$, editor. Fathers across Cultures: The importance, roles, and diverse practices of dads. Santa Barbara: Praeger/ABC-Praeger/ABC-CLIO; 2015.

90. Thabane L, Mbuagbaw L, Zhang S, et al. A tutorial on sensitivity analyses in clinical trials: the what, why, when and how. BMC Med Res Methodol. 2013. 13(1):92. https://doi.org/10.1186/1471-2288-13-92. 
91. Issaka Al, Agho KE, Renzaho AM. Prevalence of key breastfeeding indicators in 29 sub-Saharan African countries: a meta-analysis of demographic and health surveys (2010-2015). BMJ Open. 2017;7(10):e014145. https://doi.org/ 10.1136/bmjopen-2016-014145.

92. World Bank. Breastfeeding: A Smart Investment for Reaching the Sustainable Development Goals. http://blogs.worldbank.org/health/breastfeeding-smartinvestment-reaching-sustainable-development-goals. Published 2016. Accessed 15 Nov 2017

Ready to submit your research? Choose BMC and benefit from:

- fast, convenient online submission

- thorough peer review by experienced researchers in your field

- rapid publication on acceptance

- support for research data, including large and complex data types

- gold Open Access which fosters wider collaboration and increased citations

- maximum visibility for your research: over $100 \mathrm{M}$ website views per year

At $\mathrm{BMC}$, research is always in progress.

Learn more biomedcentral.com/submissions 